\title{
A fragmentação da norma de emprego na Europa. Uma comparação entre Alemanha e França'
}

OLIUIER GIBAUD:

ARNAUD LECHEUALIER

\section{Resumo}

Este artigo propõe uma análise comparativa das transformações da norma de emprego na França e na Alemanha desde o final dos anos 1980. A norma de emprego - que engloba a implantação do trabalho, sua remuneração, as modalidades de valorização das qualificações e a estabilidade no emprego - é aqui concebida a partir de uma abordagem discursiva que relaciona, na análise da ação pública, a luta pela hegemonia entre os discursos e as representações à transformação da identidade dos atores, às mudanças das relações de poder no campo das políticas públicas e às modalidades de institucionalização destas últimas. Nesses países, as transformações da norma de emprego ocorridas na virada do século resultam de uma estratégia comum de maximização dos índices brutos de emprego, cujas condições de possibilidade e consequências devem ser analisadas no contexto próprio a cada regime de emprego nacional. Os regimes de emprego são concebidos na articulação de três dimensões (LALLEMENT, 1999): a relação com o Estado e as políticas públicas, a evolução das relações de força entre os grupos de interesse, as formas de concorrência e as estruturas organizacionais nos setores pertinentes.

Essa abordagem teórica, desenvolvida primeiramente, serve para caracterizar de maneira comparativa, a seguir, os regimes e normas de emprego na França e na Alemanha até os anos 1980. A terceira parte sintetiza empiricamente uma série de mudanças no emprego ocorridas em graus diversos, nos últimos anos, nos dois países, e ressalta algumas de suas consequências em termos de redistribuição - desigual - do volume global de trabalho, de instabilidade no emprego e de aumento da pobreza laboriosa. A última parte busca explicar as modalidades da fragmentação da norma de emprego, anteriormente evidenciada, em relação

* Centre National de la Recherche Scientifique (CNRS), Centre Marc Bloch em Berlin.

** Universidade Paris 1 Panthéon-Sorbonne,, Gastprofessor na Universidade Europeia de Viadrina, Centre Marc Bloch.

1 Tradução de Patrícia C.R. Reuillard (UFRGS). 
às mutações características dos regimes de emprego nesses países, principalmente sob o ângulo da mudança discursiva nesse campo.

Palavras-chave: Normas de emprego. Políticas do emprego. Alemanha. França. Reformas do mercado de trabalho. Discursos. Agenda de Lisboa.

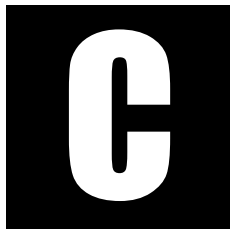

om o Tratado de Amsterdã de 1997, a promoção do emprego passa a integrar os objetivos da União Europeia (UE) e se torna uma "questão de interesse comum" dos Estados-membros (artigo 2 do Tratado que institui a Comunidade Europeia). O novo objetivo é alcançar "um nível de emprego elevado", sem enfraquecer a competitividade da União (artigo 2 do Tratado sobre a União Europeia). Para atingi-lo, atribui-se à União uma nova competência, complementar à dos Estados-membros, visando a elaboração de uma "estratégia coordenada" para o emprego. O elemento-chave dessa estratégia é constituído por diretrizes comuns e o objetivo principal pode ser resumido em uma dimensão precisa: maximizar os índices de emprego nos diferentes países-membros da União Europeia. A UE assume então as recomendações da Organização de Cooperação e de Desenvolvimento Econômico (OCDE), no final dos anos 1980 e confere a essa orientação visibilidade e eficácia novas. Nossa hipótese é de que o foco crescente das orientações estratégicas no índice de emprego, difundidas pela OCDE ou pela UE nos últimos vinte anos, criou uma oportunidade determinante para a transformação das regulações e das normas do emprego em diferentes países europeus. Essa prioridade dada ao indicador do índice bruto de emprego no âmbito da Estratégia Europeia para o Emprego (SEE) contribui para uma mudança de paradigma: o objetivo das políticas públicas não é mais, propriamente falando, a redução do desemprego a seu nível mais baixo, mas a maximização dos índices brutos de emprego inde- 
pendentemente de sua natureza e qualidade (SALAIS, 2007), o que leva a uma fragmentação das normas de emprego.

Grades de análise "institucionalistas" defendem a tese de que se assiste, tanto na França quanto na Alemanha, a uma dualização similar das normas de emprego, resultante do fracasso dos acordos de flexibilização do mercado de emprego, que poderiam ou deveriam ter ocorrido na virada dos anos 1980 para 1990 (PALIER; THELEN, 2010). O que nós queremos demonstrar é que a fragmentação da norma de emprego segue trajetórias contrastantes na França e na Alemanha. Isso se explica pelas diferenças de apropriação das orientações discursivas dominantes, formuladas em escala internacional no campo das reformas do mercado de trabalho, devido às evoluções distintas dos regimes nacionais de emprego.

A transformação que analisamos remete, acima de tudo, a uma dinâmica dos discursos e das representações e se estende por uma dezena de anos, que correspondem mais ou menos à década de 1990. Em um primeiro momento, resgatamos brevemente a dinâmica dos discursos dominantes sobre o emprego na cena internacional e europeia, ao longo dessa década, e definimos o escopo de nossa análise. Em um segundo momento, traçamos uma comparação dos equilíbrios dos sistemas francês e alemão de emprego tais como se desenvolveram até os anos 1980. Por fim, analisamos o impacto de novos discursos no campo do emprego sobre os regimes e normas de emprego desses países.

\section{Discursos e normas de emprego:}

análise da nova situação internacional e europeia

Antes de indicar os elementos-chave de nosso quadro de análise, dos vínculos entre dinâmica discursiva e normas de emprego, vamos retomar os eixos estruturantes do discurso que se impôs na cena supranacional. 


\section{Dinâmica e ambiguidade dos discursos supranacionais}

O foco das políticas do emprego no índice de emprego constitui o cerne da Estratégia Europeia para o Emprego. O Tratado de Amsterdã, já referido, foi o primeiro a enunciar a prioridade dada à "realização de um nível de emprego elevado" nos diferentes países da União Europeia. Formulado no âmbito dessa Estratégia, o objetivo de aumentar os índices brutos de emprego (número de pessoas empregadas em relação à população entre 20 e 64 anos) para 70\% (e 60\% para as mulheres) passou a ser o centro da estratégia de Lisboa, definida em 2000, na qual a UE estabelecia metas para 2010. Após o fracasso dessa estratégia, o novo documento recentemente redigido pela Comissão sobre a estratégia da UE para o ano de 2020 retoma, ampliando-o, esse mesmo objetivo e estabelece um aumento dos índices de emprego de 69 para $75 \%$ ao longo da próxima década (Comissão Europeia, 2010).

A posição defendida na época pelas redes social-democratas, tanto na Comissão, quanto nas esferas governamentais dos Estados-membros era não "exigir contraparte", mas apoiar a ideia de que o desenvolvimento do emprego é, em si mesmo, um objetivo social (BARBIER, 2010, p. 4). Na tradição social-democrata, o emprego é efetivamente a chave do acesso à cidadania social e à integração. Valorizando o capital humano, trata-se de utilizar as formações e as reconversões dos assalariados como uma política social e, ao mesmo tempo, como uma política industrial, a exemplo do que foi feito na Suécia nos anos 30 (BRAUN; GIRAUD, 2003). De acordo com essa interpretação, as causas do desemprego são macroeconômicas e devem ser buscadas nos desajustes estruturais entre oferta e procura de mão-de-obra, tanto qualitativa quanto quantitativamente.

A reviravolta nos debates sobre o emprego e a proteção social, provocada pela "revolução" neoliberal anglo-saxônica, proporciona uma interpretação alternativa. Associada ao slogan making work pay, o foco no 
nível do emprego anuncia as ambiguidades da década seguinte, em torno da noção de ativação (BARBIER, 2005). Formando a "versão liberal das políticas de ativação", a palavra de ordem making work pay (GAZIER; ZAJDELA, 2006), erigida em estratégia central pela OCDE no campo do emprego na virada dos anos 1980 e 1990, implica uma inversão das prioridades das políticas do emprego. O emprego torna-se o objetivo prioritário, antes da proteção das pessoas confrontadas aos acasos do mercado de trabalho. Desse ponto de vista, making work pay é, acima de tudo, a reformulação de outra palavra de ordem: work before welfare. Ela se concretiza em políticas do emprego, que criam uma série de medidas visando encorajar a retomada rápida de um emprego. Essa estratégia se compõe de uma série de recomendações que buscam favorecer a atividade das mulheres e promover o marketing das atividades de atendimento (care) e do conjunto dos serviços de atendimento à pessoa (LEWIS, 2010), de modo a criar um mercado dos serviços de baixa renda.

Tal estratégia se origina em uma análise que leva a uma transformação da categoria desemprego, tal como construída historicamente. Nela, o desemprego é explicado por comportamentos voluntários, decisões individuais, que levam as pessoas a preferirem o "não-emprego" ao emprego, devido a incitações insuficientes à retomada do emprego. O emprego a qualquer preço passa pela "ativação" dos desempregados. Essa leitura foi retomada e difundida pela Estratégia Europeia para o Emprego, em meados dos anos 2000 (Ibid.). A rapidez do retorno ao emprego era então apresentada como uma prioridade que permitia evitar a exclusão social ou a desvalorização progressiva das competências.

A polissemia ou, mais exatamente, a ambivalência radical de indicadores ou de noções como "índice de emprego" ou "ativação" fazem, desses termos, verdadeiros empty signifier (HOWARTH, 2000, p. 119), preciosos precisamente por sua ambivalência. A ambiguidade permite, 
então, articular discursos fortemente contrastantes (DEHOUSSE, 2004), sem, contudo, representar uma "síntese", e justificar a existência de uma área comum. O "índice de emprego" ou a "ativação" não colhem o consenso, no sentido de uma convicção ou de uma causa comum a despeito de oposições ou de divergências sobre outros elementos, como no modelo da advocacy coalition (SABATIER, 1993). Ainda que desprovidas de sentido em si mesmas, essas palavras tornam-se inteligíveis e mesmo significantes, quando inseridas em um contexto preciso de sentido. A prioridade dada ao índice de emprego é, ao menos, bivalente: tange ao mesmo tempo a valores, instrumentos e objetivos social-democratas e neoliberais. Cabe agora esclarecer como contextos nacionais e locais constituídos de atores e de formas institucionais podem reapropriar-se dos discursos.

Dinâmicas dos discursos e normas de emprego

Compreendemos os discursos sociais em uma perspectiva inspirada nos trabalhos de Myra Marx Ferree (2008). Nessa abordagem, os discursos produzidos por diferentes grupos sociais ou por organizações partidárias políticas, sindicais ou associativas atuantes no espaço público, preenchem uma tripla função. Em primeiro lugar, tais discursos visam a "enquadrar" as ações e as atitudes dos atores sociais de uma área específica, difundindo maneiras de ver, modos de interpretar, de compreender, de dar sentido a seus atos. Esse enquadramento (framing) das ações influencia as identidades e as percepções pessoais dos indivíduos e dos grupos sociais e remete, de fato, a processos de socialização. Em segundo lugar, o enquadramento das ações sociais e das identidades participa da produção de normas sociais. Com efeito, os discursos sociais visam a associar normas precisas a campos de ação pública e a formular ou reformular a problemática da ação pública, ou seja, os problemas públicos em si mesmos. Os objetivos reais de uma política pública, os beneficiários e as populações excluídas das metas, assim 
como a configuração dos atores incluídos na estrutura de governança da área de ação pública são definidos pelos discursos. Enfim, em terceiro lugar, o enquadramento das ações e das identidades, a reformulação dos problemas públicos e suas conseqüências sobre as relações de poder no campo de ação pública constituem as bases de um processo de institucionalização.

Relacionando a luta pela hegemonia entre discursos sociais à transformação das identidades dos atores em campo e de seus modos de ação, às mudanças nas relações de poder em uma área de ação pública e às condições da institucionalização, a abordagem proposta por Myre Ferree permite englobar as dimensões-chave da mudança no campo das políticas públicas.

Normas e sistemas de emprego

As normas sociais justificam, em um determinado período, o acordo político que expressa um conjunto de práticas e quadros cognitivos da interação social, nesse caso, no campo do emprego. Em sua dimensão discursiva, as normas de emprego remetem à luta pela hegemonia na construção da realidade social. Em sua dimensão de socialização, influenciam as identidades e as práticas dos atores. Em sua dimensão de institucionalização, elas são, enfim, a tradução em regras dos acordos políticos dominantes. Tal como aqui concebida, a norma não é, portanto, uma média dos comportamentos observáveis em um sentido durkheimiano, mas um "painel indicador" (Wittgenstein), cujo sentido - o jogo que se deve jogar - é dado pelas práticas de coordenação.

Os determinantes das normas de emprego situam-se na articulação entre as transformações estruturais nas sociedades e as abordagens discursivas concorrentes que presidem à sua interpretação. As transformações estruturais remetem às dinâmicas socioeconômicas de longo prazo (terciarização da economia, internacionalização das economias e transformações das formas produtivas, mudança das estruturas demográficas e 
familiares, dinâmica das formas de ação coletiva, etc.) que modificam as dimensões constitutivas dos regimes de emprego (cf. infra).

A mudança nessas normas pode ocorrer quando, sob o efeito das evoluções da realidade social - neste caso, a transformação dos sistemas de emprego -, sua faculdade para constranger os comportamentos e para arbitrar os conflitos é questionada em um dado contexto ou, mais ainda, quando o próprio conteúdo da norma é questionado. Essa contestação das normas assume a forma de um novo registro discursivo, que modifica o papel e a identidade dos atores pertinentes e torna necessárias reordenações institucionais. Nesse sentido, o controle da expertise é um elemento determinante.

Para compreender os efeitos do novo registro discursivo centrado no aumento dos índices de emprego na Alemanha e na França, acrescentamos à nossa análise uma grade sintética e comparativa dos sistemas de atores e instituições no campo do emprego nesses países e das transformações que sofreram nas duas últimas décadas. Desse ponto de vista, Michel Lallement propõe uma grade de análise muito útil dos regimes de emprego, que remete a três mecanismos principais (LALLEMENT, 1999, p. 42-48). O primeiro deles corresponde à relação com o Estado. As normas do emprego e, sobretudo, os procedimentos anteriores de negociação dessas normas (as delegações de poder a certos atores, a força e a área de aplicação das normas negociadas, etc.) inscrevem-se em uma relação com a autoridade pública. Esta inicia, rejeita, orienta, ou estende as normas que decorrem de regulações privadas de diferentes níveis e qualidades. A regulação pública direta do setor de emprego, assim como um grande número de políticas públicas, quer sejam políticas sociais - familiares, por exemplo -, quer tanjam diretamente ao emprego, também exercem um impacto determinante sobre o emprego (LEFRESNE, 2005, p. 406). O segundo desses processos remete à autoridade social dos grupos de interesses. Conforme suas capa- 
cidades de organização e seus modos de estruturação - principalmente intersetoriais, territoriais e entre grupos profissionais -, as organizações encarregadas da regulação do emprego conseguem negociar acordos mais ou menos abrangentes, subjugantes ou progressistas. Enfim, o terceiro mecanismo remete às formas de concorrência e estruturas organizacionais que regulam os diferentes setores econômicos e sociais de atividade. As estratégias dos empresários, das instituições, dos níveis e formas de concorrência nos mercados (HALL; SOSKICE, 2001) têm um efeito direto sobre as regulações dos regimes de emprego.

Dinâmica comparada dos regimes e das normas de emprego na França e na Alemanha até a década de 1980

Utilizaremos agora esta grade de análise para sintetizar as principais características dos regimes e das normas de emprego nesses países até os anos 1980 e, posteriormente, comparar com as transformações ocorridas. A relação com o Estado

Há disparidades marcantes nesses dois países no que diz respeito a essa primeira categoria de análise. De fato, a influência do Estado na regulação do campo do trabalho e do emprego é manifesta na França. Em primeiro lugar, desde os anos 1950, o Estado fixa um salário mínimo, que garante uma homogeneidade salarial forte para os baixos salários e determina a duração legal do trabalho. Em segundo lugar, o Estado enquadra a atividade convencional dos parceiros sociais (BEVORT; JOBERT, 2008, p. 77). Os instrumentos-chave dessa política são a extensão automática, a todas as empresas de um setor, dos acordos assinados entre sindicatos e associações patronais e julgados representativos pela lei, ou as medidas legais de obrigações a serem negociadas. Em último lugar, as 
políticas educativas e do emprego são meios de ação sobre as regulações do emprego. $\mathrm{O}$ acompanhamento das reconversões, as políticas de inserção pelo econômico, ou as aposentadorias antecipadas dos assalariados idosos, principalmente na indústria, são exemplos bem conhecidos disso.

Na Alemanha, a influência do Estado constrói-se de maneira mais indireta. Com efeito, mais do que intervir no conteúdo das normas, a ação do Estado alemão incide sobre a definição de procedimentos que devem, a seguir, ser adotados pelos atores da área. Nesse caso, o Estado desenvolveu, ao longo de uma movimentada história (THELEN, 1991; GIRAUD; LALLEMENT, 1997), um sistema de relações profissionais que busca manter a capacidade de negociação das associações patronais e sindicais. Mas, nem por isso, a autonomia tarifária é um princípio de neutralidade: defendendo a autonomia das negociações entre patrões e sindicatos, o Estado alemão ocidental, sobretudo em sua versão ordoliberal no período imediato ao pós-guerra, defendia um lugar central para a norma de mercado. Definidas de modo autônomo, as normas de emprego, de salário, de tempo e condições de trabalho, de qualificação, etc., variam muito de um ramo a outro. O controle paritário por sindicatos e empregadores do conselho de administração da Agência Federal do Emprego é outra indicação dessa configuração de poder. Para além dessas diferenças, o papel estabilizador desempenhado pelo Estado empregador no setor dos serviços (BOSCH, 2008; LALLEMENT, 1999) e o alto nível de proteção legal da relação de emprego representam importantes pontos em comum. Na França, o Estado encarrega-se da implantação dessas proteções, ao passo que, na Alemanha, elas competem aos parceiros sociais. Autoridade dos grupos de interesse

Como se pode ver, a regulação alemã do emprego atribui um papel importante às organizações patronais e sindicais. Na Alemanha, essas or- 
ganizações são poderosas, bastante integradas horizontal e verticalmente. No campo sindical, a DGB, confederação dominante de esquerda, malgrado sua relativa heterogeneidade ideológica, conseguiu reduzir a influência de seus concorrentes realizando praticamente o programa do sindicato unitário, ambicionado por Hans Böckler ao final da Guerra. A liderança do sindicato da metalurgia (IG Metall) contrasta com a fragilidade de seus homólogos no artesanato e nos serviços, à exceção dos serviços públicos. O campo patronal não promove a solidariedade intersetorial, já que os empregadores - assim como os sindicatos de assalariados na indústria exportadora (CARLIN; SOSKICE, 2008) - extraem uma boa vantagem dos diferenciais da norma de emprego entre ramos.

$\mathrm{Na}$ França, essas disparidades nas capacidades organizacionais dos diferentes setores acompanham-se não só de uma fragilidade estrutural das organizações patronais, divididas e enleadas em uma concepção orgânica e patrimonial da empresa, mas também da fragilidade e de fortes tensões ideológicas entre organizações sindicais. Depois das décadas do pós-guerra, marcadas pela extensão dos confrontos, o desenvolvimento de um sindicato de negociação e a reorganização do patronato na virada dos anos 1960 para 70 levaram a um processo de apaziguamento relativo (BEVORT; JOBERT, 2008). A fragilidade endêmica das organizações sindicais é, em parte, compensada pela autoridade do Estado, que desempenha um papel de incentivo e de coordenação, ao orientar a negociação social através da política das infraestruturas, da política industrial ou do jogo da circulação das elites entre Estado e grandes empresas.

Formas de concorrência e estruturas mercantis

As formas de concorrência e estruturas mercantis também são diferentes, de um lado e outro do Reno. Na França, o Estado é proprietário das empresas mais importantes em numerosos setores-chave até os anos 
1980. O elo entre Estado e grandes empresas é reforçado pela seleção dos dirigentes das empresas via escolas de ensino superior, as chamadas grandes écoles, e pela circulação das elites entre a alta função pública e as direções de empresas, que negociam diretamente as condições econômicas e sociais de seu desenvolvimento (BERREBI-HOFFMANN et alii, 2009). Em compensação, a dominação das grandes empresas nas organizações representativas do patronato, não permite engrenar dinâmicas cooperativas entre as firmas, principalmente de diferentes tamanhos, na negociação da norma de emprego.

Na Alemanha, o patronato das grandes empresas controla as questões centrais no âmbito de relações interempresariais, principalmente entre grandes e pequenas, centradas na cooperação. As grandes empresas, sobretudo dos setores poderosos da exportação - por exemplo, o setor automobilístico, químico, de máquinas-ferramenta -, negociam exigentes normas salariais ou de qualificação e impelem as PME de seu ramo, frequentemente fornecedores, a uma melhoria constante do desempenho produtivo. Os maiores grupos alemães da construção mecânica ou da química construíram, a partir dos anos 1960, uma norma de emprego que repousa sobre a garantia do emprego e sobre promoções internas escalonadas, que só existem, na França, para os executivos das maiores empresas.

Normas de emprego até os anos 1980

No caso da França, o intervencionismo do Estado na definição da norma de emprego é um dos elementos da condução macroeconômica. O enquadramento das regulações convencionais pelo Estado tem a finalidade de moderar as desigualdades intersetoriais nas condições, formas e remunerações do emprego. Esse intervencionismo estatal na norma de emprego pode ser analisado como a declinação de uma cidadania republicana que busca criar uma forma de integração e de proteção ativa pelo 
Estado e vem compensar a fragilidade dos sindicatos e das associações patronais. A norma de emprego à francesa soube primeiramente resistir bem à crise dos anos 1970. O acordo de crescimento, integrador, foi desenvolvido no sentido de um fortalecimento das proteções ao emprego (Autorização Administrativa de Demissão, no caso dos representantes sindicais) e do desenvolvimento de políticas de emprego e de formação a fim de proteger supostamente os assalariados mais frágeis e indenizar convenientemente os desempregados. A partir dos anos 1970, com o aumento do desemprego, os trabalhadores idosos, os jovens e as mulheres revelam-se as principais vítimas das lacunas do regime de emprego à francesa e das normas que ele gerou. As políticas sociais e familiares certamente favorecem a atividade feminina, mas não são políticas de igualdade dos gêneros. O trabalho feminino é, sobretudo no caso das classes mais modestas, um trabalho complementar, que os dispositivos públicos levam a opor permanentemente, ainda que a originalidade francesa resida na predominância da norma de emprego em tempo integral para as mulheres.

No caso alemão ocidental, a ausência de salário mínimo, de intervenção pública no nível das qualificações ou no tempo de trabalho, etc. indicam, em contrapartida, o lugar central reconhecido ao mercado e às negociações entre sindicatos e empregadores. A autonomia relativa dos diferentes setores autoriza a manutenção de disparidades intersetoriais, que se atenuam em períodos de crescimento. A relação cidadã com o emprego não é diretamente garantida pelo Estado, mas resulta de uma série de pertenças encadeadas. A profissão e o setor (associações profissionais, sindicatos), a empresa (conselho de empresa), o sistema de proteção social (programa de seguro-desemprego) são as organizações, tradicionalmente fortes e com estruturas de controle interdependente, que dão vida a essa cidadania pelo emprego. 
Até o início dos anos 1980, a Alemanha Ocidental praticamente escapou ao aumento do desemprego que grassava nos vizinhos. O desempenho da indústria alemã na exportação influenciou favoravelmente os setores de atividade como um todo. As crises industriais de reestruturação concentradas em certas bacias de emprego não desestabilizaram o regime alemão do emprego. Entretanto, a crise dos anos 1980 estancou pela primeira vez e de modo breve a retomada progressiva dos setores fortemente remuneradores por aqueles que o são menos. As principais vítimas foram os jovens aprendizes desses setores pouco valorizantes e principalmente os trabalhadores mais velhos dos setores em reestruturação. Quanto às mulheres, até os anos 80 elas permanecem menos presentes no mercado de trabalho do que a maioria das europeias. O regime fiscal, as políticas sociais, familiares e escolares desencorajam a atividade feminina.

\section{Transformações dos regimes e das normas de emprego na França e na Alemanha}

Esta parte é dedicada ao exame das mudanças estruturais nos regimes e nas normas de emprego na França e na Alemanha, desde o final dos anos 1980. Na seção seguinte, explicamos essas transformações bem específicas em cada uma desses países, pelos modos distintos de reapropriação dos discursos dominantes sobre o emprego na cena internacional.

Regimes de emprego em mutação

Na França, o Estado renova, nos anos 1990, sua maneira de investir no campo do trabalho e do emprego. Em primeiro lugar, o Estado central apartou-se de importantes recursos de poder, ou favorecendo a descentralização em nível regional - diálogo social regional - (JOBERT; HEIDLING, cap. XX) e, no da empresa, das relações profissionais, ou atra- 
vés da transferência de suas competências às regiões na área da formação profissional. Em segundo lugar, a política de isenção dos encargos sociais para os baixos salários contribuiu para inverter a tendência à diminuição dos empregos de baixos salários no emprego total. Somando-se ao forte crescimento dos empregos em tempo parcial - ele mesmo encorajado pela isenção de encargos a partir de 1992 - até o início dos anos 2000, essa política voluntarista favoreceu a emergência de uma nova norma de emprego às margens do mercado de trabalho: os baixos salários com duração parcial do trabalho ao longo do ano. A partir daí, foram progressivamente instaurados diversos mecanismos de incentivo ao emprego para os beneficiários de prestações sociais, cuja lógica foi coroada por um dispositivo de renda mínima, a Renda de Solidariedade Ativa. Entre isenção de encargos sociais e complementos salariais pagos pela autoridade pública, as políticas de emprego na França levaram a uma socialização, sem equivalentes, do setor de baixos salários, sem impor contrapartidas às empresas envolvidas (GAURON, 2008).

Na Alemanha, o Estado procedeu a um sério aggiornamento da orientação e também do perímetro de regulação no campo do emprego. As dificuldades macroeconômicas que se seguiram à reunificação (BIBOW, 2001) levaram as grandes empresas dos setores exportadores a optar por uma política de "nova desinflação competitiva" (CHEVILLON et alii, 2007), traduzida por uma pressão sobre os custos salariais e por reforma tributária, dos seguros sociais e do mercado de trabalho. Essa orientação foi acompanhada por processos de outsourcing e por uma expansão crescente da economia alemã (a parcela das exportações imputada ao PIB passou de 26\% para 47\% entre 1996 e 2007 e a das importações, de $23 \%$ para $39,6 \%$ ). Na linha do programa Blair-Schröder, a criação de um setor de baixo salário foi encorajada pela recuperação do teto de remuneração dos pequenos trabalhos isentos total ou parcialmente de 
encargos sociais assalariados (os chamados mini e midijobs) e pelo recurso à margem ao imposto negativo para os beneficiários dos salários mínimos. Essa pressão sobre os custos nos serviços representa uma importante vantagem competitiva para a indústria de exportação, que agora adquire serviços no mercado em condições vantajosas de preço. Na ausência de salário mínimo interprofissional, ela acentua igualmente as disparidades salariais entre a indústria exportadora e os serviços (DÜTHMANN et alii, 2006). Enfim, a reforma das políticas de emprego completou essa agenda através da gestão por objetivos do partido social-democrata europeu SPE, da redução do período de indenização, da fusão do seguro-desemprego para os desempregados de longa duração e da ajuda social bem como da ativação dos desempregados de longa duração pela reformulação aceitável das condições do emprego.

No plano das organizações do mundo do trabalho, na França, a transformação do Conselho Nacional do Patronato Francês (CNPF), em Movimento das Empresas da França (MEDEF) insere-se em uma estratégia de definição da agenda das reformas, testemunhada pelo programa ofensivo da "refundação social" (VAIL, 2008). Habituadas ao jogo das negociações políticas e hábeis em barganhar e manipular o apoio do Estado, as associações patronais buscam despontar como atores da inelutável modernização. Os sindicatos permanecem fracos, divididos, dependentes do Estado para sua sobrevivência financeira e são, acima de tudo, organizações institucionalizadas. Entretanto, o sindicalismo de negociação adquiriu importância, inclusive na Confederação Geral do Trabalho (CGT) e soube investir em um diálogo social territorial, que lhe confere uma nova influência nas áreas da inserção pelo econômico, da formação ou do desenvolvimento local (JOBERT, 2000).

Na Alemanha, a reorientação da norma de emprego iniciada pelo Estado constitui um verdadeiro desafio para os atores do campo das re- 
lações profissionais. Desde meados dos anos 1990, um importante movimento de flexibilização das convenções coletivas precedeu as medidas recentes de flexibilização do mercado de trabalho. Hoje em dia, menos de $40 \%$ das empresas ocidentais e menos de $20 \%$ das empresas orientais estão ligadas a uma convenção coletiva (BISPINCK, 2007). Além disso, os sindicatos concederam múltiplas formas derrogatórias às convenções coletivas. As cláusulas de aberturas (Öffnungsklausel) que dizem respeito a uma maioria de empresas, as convenções coletivas de empresas ou as alianças de empresas para o emprego (betriebliche Bündnisse für Arbeit) são medidas de defesa do emprego que remetem, de fato, a um movimento intenso de descentralização e de flexibilização da definição da norma de emprego. Salários, tempo e organização do trabalho são as questões mais importantes dessa dinâmica (EICHHORST; MARX, 2009).

Enfim, também as estruturas de mercado transformaram-se nos dois países. Na França, duas principais dinâmicas despontaram: em primeiro lugar, como na Alemanha, observa-se um desenvolvimento significativo do setor dos serviços às margens das normas de emprego institucionalizadas; em segundo lugar, a França passou de um regime de capitalismo dirigido pelo Estado a uma grande autonomização das grandes empresas. Esse enfraquecimento do Estado se explica pela descentralização da ação pública e pelas ondas de privatização; o Estado renovou seus instrumentos de condução industrial por meio da reorganização do ensino superior e da busca e instauração dos "polos de competitividade". Uma mudança gradual permitiu às grandes empresas construir um novo ambiente de acordo com suas próprias preferências (BERREBI-HOFFMANN et alii, 2009).

Do lado alemão, a saída de um número considerável de empresas do quadro tarifário, as reformas do Estado social (em particular, o fortalecimento da indenização do desemprego) e a política de compressão dos custos salariais transformam as formas de concorrência, mas também de 
solidariedade que se haviam forjado no modelo socioeconômico ocidental alemão, anterior à reunificação. Primeiramente, as empresas da construção mecânica, da química, ou os serviços às empresas reinventam um modelo de competitividade que não renuncia às modalidades de fundo de seu investimento da mão-de-obra, mas implantam práticas de terceirização maciça dos serviços anexos (restauração, transportes, informática, etc.), que correspondem a uma transformação importante da posição das empresas alemãs em relação a seu mercado e que alimentam o debate sobre "a economia de bazar" (SINN, 2005). Elas são encorajadas por uma transformação das relações entre a indústria e seus financiadores. As relações de longo prazo e o sistema das participações cruzadas eram considerados os pilares do modelo capitalista alemão (HALL; SOSKICE, 2001). Essas relações privilegiadas transformaram-se muito hoje em dia (BOSCH, 2008), e o capital das empresas alemãs tornou-se "impaciente".

A fragmentação da norma de emprego: modalidades diferenciadas na Alemanha e na França

Desde o início dos anos 1990 e até o desencadeamento da crise atual, o índice de emprego dos dois países aumentou significativamente. Assim, a França registrou um crescimento da ordem de um quinto do emprego interno, equivalente ao da UE e próximo do índice dos Estados Unidos. Entre 1995 e 2007, o índice global de emprego na categoria entre 15-64 anos passou de 60 para 65\% e de 73 para $80 \%$ para os indivíduos entre 25-59 anos. A Alemanha, cujo emprego havia baixado nos anos 1990, viveu dois períodos de retomada do emprego: 1998-2001 e principalmente 2005-2008, quando viu o índice de emprego dos 15-64 anos saltar de 65 para $70 \%$ (75 para 80\% entre 25-59 anos). Em ambos os países, porém mais ainda na Alemanha, esse aumento do emprego é quase inteiramente imputável às mulheres, cujos índices brutos progrediram 
10 pontos percentuais entre 1998 e 2008 (55 e 65\%) contra 7 pontos percentuais na França. Esse aumento dos índices de emprego acompanha-se de uma modificação da norma de emprego em termos de qualificação, tempo de trabalho, estabilidade no emprego e remuneração.

O impacto dos movimentos de entrada e de saída do mercado de trabalho, em termos de qualificação é distinto nesses países. Na Alemanha, tradicionalmente a parcela dos assalariados com qualificação intermediária é nitidamente superior àquela dos demais países europeus, de modo que a parcela dos assalariados pouco qualificados é duas vezes menor que nos outros países da Zona Euro (10 contra 21\%). A originalidade da Alemanha no período mais recente é que foram as mulheres com uma qualificação média (principalmente) ou muito alta que entraram no mercado de trabalho, enquanto os índices de emprego das mulheres com pouca qualificação estagnaram. O aumento dos índices de emprego por nível de qualificação é mais homogêneo na França, mas um pouco maior para as mulheres com pequena qualificação.

Em que condições se deu essa entrada das mulheres alemãs (qualificadas) no mercado de trabalho? O surgimento do emprego em tempo parcial e os "pequenos trabalhos" transformaram a norma de emprego para uma parcela crescente do salariado, essencialmente feminino. Contudo, a fragmentação da norma de emprego é mais pronunciada na Alemanha do que na França. De 1992 a 2007, a duração anual média do trabalho diminuiu exatamente o mesmo volume de horas anuais nos dois países e mais depressa do que nos outros países da OCDE (exceto naqueles em que ela era muito elevada originalmente, a Coréia e o Japão). Porém, enquanto a contribuição do tempo parcial explica $86 \%$ da diminuição alemã, ela fica limitada a 14\% na França (INSEE, 2010). Neste país, as leis sobre a redução da duração legal do trabalho (1998 e 2000) permitiram uma certa negociação da redução do tempo do trabalho no nível das empre- 
sas. A parcela de mulheres com trabalho em tempo parcial (30\%) recuou ligeiramente nos últimos dez anos e a duração média do tempo parcial progrediu. A norma de emprego continua sendo o tempo integral, inclusive para as mulheres, mesmo que, cada vez menos, tenham acesso a ele ao longo do ano. O volume global de horas trabalhadas na economia progrediu 10\% na França entre 1997 e 2007, mas baixou na Alemanha desde o início dos anos 1990: ou seja, neste país o aumento dos índices brutos de emprego deve-se inteiramente a uma redistribuição do volume global de trabalho entre um número crescente de assalariado(a)s. Lá, a parcela do emprego em tempo parcial dobrou nos últimos 25 anos e, em cada duas alemãs entre 25 e 59 anos, uma trabalhava em tempo parcial em 2008, numa jornada semanal menor do que na França (18h). O aumento dos índices brutos globais de emprego em 4,3 e 5 pontos percentuais na Alemanha e na França, respectivamente entre 1997 e 2007 traduz-se, convertido em índice de emprego em equivalente tempo integral (TETP), por um aumento reduzido a 2,5 pontos percentuais na França e por uma diminuição na Alemanha, nos últimos quinze anos (de 60,5 para 59,6).

É precisamente aqui que surge uma segunda categoria de questões, que gira em torno da estabilidade do emprego e de sua distribuição desigual. Essa estabilidade, medida pela antiguidade média dos assalariados na empresa, em uma determinada data, não diminuiu nos anos 1980 e 1990 nos países da União Europeia, assim como a parcela da duração de emprego superior a dez anos (AUER; CAZES, 2003). Na Alemanha e na França, entre 1992 e 2007, a antiguidade no emprego até mesmo progrediu em média. Em compensação, o número de transições do emprego para o desemprego aumentou significativamente. Assim, na realidade, a estabilidade da antiguidade média no emprego dissimula desigualdades crescentes entre assalariados, conforme a geração, o sexo e o nível de qualificação. Embora o contrato de duração indeterminada e em tempo integral continue sendo 
a forma predominante de emprego, a estabilidade no emprego é cada vez mais desigual, e os empregos atípicos predominam nos movimentos do mercado de trabalho. Na Alemanha, a parcela dos empregos "atípicos" no emprego assalariado passou de 18 para 33\% entre 1991 e 2007, com um crescimento muito constante dos minijobs ao longo do período recente: $5 \%$ dos empregos em 1997 e 11\% em 2007 (SVR, 2007). Na França, a parcela dos empregos assalariados que não contam com tempo integral ao longo do ano (tempo parcial, intermitentes e interinos) passou de 17 para 31\% entre 1978 e 2005 (de 22 para 41\% para os assalariados).

A terceira mudança diz respeito à expansão do setor de baixos salários e às desigualdades salariais. Habitualmente, os baixos salários são definidos de maneira relativa, por um limiar apreendido relativamente ao salário horário mediano, em geral, dois terços deste. Por essa medida, a proporção dos baixos salários progrediu cerca de 7 pontos percentuais na Alemanha entre 1998 e 2007, de modo que o setor de baixos salários passou a ser, desde o início dos anos 2000, tão importante quanto nos Estados Unidos (BOSCH; WEINKOPF, 2008; KALINA; WEINKOPF, 2009). A situação não é a mesma na França, onde a incidência dos baixos salários, também apreciada em termos de salário horário, é nitidamente inferior e, após ter progredido nos anos 1980, vem baixando desde então, pelo menos até 2002 $(12,7 \%)$. Além disso, as probabilidades de sair do setor de baixos salários após um ano eram, na França (34,5\%), na segunda metade dos anos 1990, superiores à média dos países da UE-15 (30,7\%) e mais ainda na Alemanha (25,4\%); os índices de saída após 7 anos eram de 70\% na França e de 50\% na Alemanha no mesmo período (CAROLI; GAITIÉ, 2008, p. 44). A existência do salário mínimo (SMIC), a política de revalorização desse salário - possível nos últimos anos devido à política de isenção dos encargos sociais - e seu efeito de compressão para baixo da distribuição dos salários são fatores explicativos-chave dessas diferenças entre os dois países. 
O aumento substancial do setor de baixos salários na Alemanha vem inscrever-se em um contexto mais geral de aumento significativo das desigualdades salariais desde 1997 (GERNANDT; PFEIFFER, 2006) e, de modo mais geral, das desigualdades de renda nos últimos quinze anos, que encontra poucos equivalentes entre os países desenvolvidos (OCDE, 2007). A situação é diferente na França, onde as desigualdades salariais entre salários em tempo integral continuaram a declinar de 1990 a 2005, à exceção da parcela bem superior de distribuição dos salários. Ali, é o aumento dos empregos com horários atípicos ao longo do ano, que explica o aumento das desigualdades salariais (ABEBERHARDT et alii, 2007).

Em suma, não se pode falar de uma mera "dualização" do mercado de trabalho que, além disso, seria similar nesses dois países (PALIER; THELEN, 2010). A fragmentação da norma de emprego traduz-se por um continuum de situações diversificadas e cada vez mais desiguais em relação ao emprego. Embora seja comum aos dois países, essa evolução é nitidamente mais pronunciada na Alemanha onde o aumento dos índices de emprego das mulheres qualificadas traduziu-se, mais do que na França, pela expansão dos empregos atípicos, da pobreza laboriosa e das desigualdades salariais.

Formas distintas de apropriação dos regimes discursivos sobre o emprego nos anos 1990

Na França e na Alemanha, a mutação da norma de emprego é resultado do investimento de atores nacionais em um novo registro discursivo e em novos quadros interpretativos da situação do emprego e do desemprego, difundidos por organizações internacionais como a OCDE e a União Européia desde o final dos anos 1980. Em ambos os países, dinâmicas políticas combinaram-se às transformações socioeconômicas para ex- 
plicar a reapropriação dos discursos dominantes no contexto internacional. Entretanto, os processos em ação são bem diferentes. Na França, a reforma iniciada pelo Estado, após uma mudança profunda da expertise do Estado e com o apoio do patronato, desemboca na focalização dos problemas públicos na problemática do custo do trabalho não-qualificado e nas incitações a empregar-se. Na Alemanha, precedida por um debate público nos anos 1990, sobre a competitividade da economia alemã (Standortdebatte), a transformação implica uma redistribuição das cartas de poder na área e no questionamento das formas clássicas da cidadania no emprego. Vamos primeiramente delinear, em grandes traços, a evolução das normas de emprego instituídas nos dois países desde os anos 1990, antes de retomar os discursos e as formas de expertise que impuseram tais orientações.

$\mathrm{Na}$ França, as primeiras reformas importantes começam em meados dos anos 1989, com a supressão da autorização administrativa de demissão. A lei quinquenal de 1993 contribui muito, em seguida, para a redefinição da norma de emprego: acordos empresariais de flexibilização e anualização da jornada de trabalho, fortalecimento do controle dos desempregados, descentralização da formação profissional e da negociação social, criação dos cheques emprego-serviço*, mas, principalmente, indenização parcial dos encargos sociais para a totalidade dos baixos salários, estendidos até 1,3 SMIC a partir de 1995 e, atualmente, a 1,6. Na virada do século, o governo do primeiro-ministro Lionel Jospin, através da política das 35 horas, generaliza a estratégia de redução/distribuição da jornada de trabalho e amplia consideravelmente a política de isenção dos encargos sociais. A instauração do Prêmio para o Emprego, auxílio para o retorno ao trabalho e à manutenção da atividade profissional, responde, por sua vez, ao duplo objetivo de concretizar o making work pay e reduzir

\footnotetext{
* Meio de pagamento, pré-financiado parcial ou totalmente por uma empresa, que permite pagar serviços a terceiros. (N. de trad.)
} 
as desigualdades de renda. Com a volta de governos conservadores, as noções de empregabilidade, de individualização do tratamento do desemprego, de flexibilização das relações de emprego (contratos CNE e $\mathrm{CPE}$, que regem as novas e as primeiras contratações), acompanhadas de medidas simbólicas para assegurar situações e percursos profissionais, são apresentadas como a construção de uma "flexiguridade" - flexibilidade e seguridade - à francesa (BARBIER, 2008).

No caso da França, a modificação da norma de emprego passa pelo papel desempenhado pela expertise, com a conversão da elite tecnocrática às teses neoliberais, iniciada nos anos 1970, e por uma tomada do poder por economistas estatísticos, progressiva, mas quase sistemática (JOBERT; THÉRET, 1994; BARBIER, 2008). Essas redes (INSEE, gabinete do primeiro-ministro, Ministério da Fazenda e Conselho de Análise Econômica) representaram um papel-chave na política de diminuição dos encargos sociais sobre os baixos salários e, posteriormente, na instauração de uma forma de crédito de imposto, destinado a "tornar o trabalho mais remunerador", com o Prêmio para o Emprego (COLOMB, 2009). Em ambos os casos, o registro neoliberal da prioridade conferida ao índice de emprego domina largamente.

$\mathrm{Na}$ Alemanha, medidas iniciais de liberalização do mercado de trabalho - fortalecimento das condições de indenização de desemprego - e de redução das despesas ativas para o emprego, tomadas nos últimos anos da coalizão cristã-democrata de Helmut Kohl, justificam-se no âmbito do importante Standortdebatte consagrado às reformas necessárias para enfrentar os desafios da globalização, mas também da perspectiva da integração à Zona Euro (SIEGEL, 2002). Em 1996, o fracasso dos "pactos pelo trabalho e pela segurização da produção na Alemanha" demonstra o distanciamento dos sindicatos da "agenda reformadora" e reativa no país a temática do declínio e da incapacidade do modelo nacional para se 
reformar (Reformstau). De fato, esse debate nacional prepara o país para as rupturas da legislatura seguinte.

O programa da coalizão vermelho-verde que chegou ao poder em 1998 com Gerhard Schröder, recusa a estimulação orçamentária, anuncia a redução das deduções obrigatórias, a "modernização" do Estado social e o desenvolvimento das políticas familiares (SEELEB-KAISER; FLECKENSTEIN, 2007). O fracasso de uma estratégia de acordo entre a ala esquerda, próxima dos sindicatos, e a ala centrista do SPD, o Partido Social Democrata, representada pelo chanceler Schröder, abre uma seqüência de mudanças radicais. O "Programa Blair-Schröder" (1999) revela-se agora a referência programática, não negociada, da agenda 2010 de reforma social, principalmente do setor do emprego então lançado pelo governo. No cerne da argumentação, encontra-se a ideia de que as normas do trabalho da era industrial não podem ser aquelas da "economia do futuro", que é uma economia dos serviços e do conhecimento. Esse programa político ressalta a responsabilidade individual dos que procuram emprego e preconiza o desenvolvimento do tempo parcial e de um setor de baixos salários que torne disponíveis empregos com baixa qualificação (BLAIR, SCHRÖDER, 1999). Essa interpretação segue uma série de diagnósticos que estimam classicamente que o nível geral do emprego é insuficiente na Alemanha, em relação, por exemplo, ao dos Estados Unidos, devido à fragilidade do emprego no setor dos serviços pouco qualificados à pessoa (SCHARPF; SCHMIDT, 2001; EICHHORST; KAISER, 2006).

Essa mudança de discurso acompanha-se de uma profunda modificação da expertise mobilizada. Em 2000, um grupo de experts fora encarregado de assistir cientificamente as negociações tripartites para um "pacto para o emprego". Composto exclusivamente de universitários especialistas da área, considerados próximos da corrente modernizadora do SPD e apoiando-se em um benchmarking sistemático das políticas dos 
principais países da OCDE (EICHHORST et al., 2001), os trabalhos afirmam, ao mesmo tempo, a segurança dos percursos e a prevenção do desemprego, enquanto insistem sobre a responsabilização dos assalariados, dos desempregados, mas também das empresas em sua função de formação (CHAGNY, 2005). Esse grupo desempenhou um papel crucial, principalmente por incluir na agenda a importância de assumir os desempregados de longa duração (FLECKENSTEIN, 2008) e por recorrer ao índice de emprego como critério de avaliação da política do mercado do trabalho, complementado na época por considerações sobre a qualidade dos empregos (SCHMID, 2002).

Na trilha do escândalo que atinge o Serviço Público do Emprego alemão, o governo Schröder veste o processo das reformas posteriores das políticas para o emprego com a roupagem de Peter Hartz, ex-chefe de pessoal da Volkswagen, empresa celebrada ao longo dos anos 1990, por seus acordos empresariais inovadores. Hatrtz constitui uma comissão de experts onde predominam os representantes do mundo empresarial ou de gabinetes de consultores internacionais. A comissão Hartz desviase das formas tradicionais de expertise na Alemanha e anuncia uma nova etapa na ruptura do consenso sobre o emprego e as políticas do emprego (RUDISCHHAUSER; ZIMMERMANN, 2004, p. 278). Outra ruptura essencial, o Chanceler compromete-se formalmente a executar "ao pé da letra" as decisões da comissão. Esta recomenda a integração da assistência aos desempregados e do auxílio social, no âmbito de uma prestação, sob condição de recursos, prepara o avanço progressivo para uma "ativação negativa" dos desempregados e formaliza de maneira geral a nova agenda das políticas do emprego, conduzida paralelamente, há muito, por uma expertise econômica cada vez mais monocromática, à imagem das recomendações reiteradas de relatório em relatório pelo "Conselho dos Sábios" na área da política macroeconômica. Esse processo anuncia a 
ruptura entre a ala esquerda do SPD (fundação do WASG e depois, fusão com o PDS no partido Die Linke).

No caso da França, a apropriação da valência neoliberal do discurso de priorização do índice de emprego é a tal ponto centrada nas redes de expertise e políticas estatais que fica difícil evocar uma forma ou outra de negociação social. Na Alemanha, a mudança é mais espetacular ainda. O final da gestão tripartite do conjunto do setor do trabalho e do emprego remete a uma transformação mais radical das relações de poderes em campo. O enfraquecimento político dos sindicatos representou uma etapa necessária na via da organização da fragmentação da norma de emprego.

\section{Conclusão}

As normas sociais dão conta, para um determinado período, do acordo político que expressa um conjunto de práticas e de quadros cognitivos da interação social, neste caso, no campo do emprego. Tentamos mostrar que os determinantes das normas de emprego estão situados na articulação entre transformações estruturais nas sociedades e abordagens discursivas concorrentes que presidem à sua interpretação. Essas abordagens discursivas remetem à luta pela hegemonia na construção da realidade social. No campo das políticas públicas, elas influenciam as identidades e as práticas dos atores envolvidos; contribuem para definir as questões em jogo na ação pública, seu conteúdo e seus públicos alvos; são, enfim, a tradução em forma de regras dos acordos políticos dominantes. A análise da transformação da realidade social foi, por sua vez, conduzida aqui a partir de uma grade de análise centrada nas interações entre três dimensões constitutivas dos regimes de emprego (LALLEMENT, 1999): a relação com o Estado, a autoridade social dos grupos de interesse e as formas de concorrência nos mercados. 
A partir desse quadro teórico, buscamos mostrar que, desde a metade dos anos 1990, os regimes de emprego alemão e francês haviam sofrido transformações profundas, mas contrastadas, sob o efeito do discurso, formatado pela expertise, do emprego "a qualquer preço". O conteúdo da nova agenda para as políticas do emprego difere pouco na Alemanha e na França quanto ao quadro conceitual de referência, que imputa as causas do desemprego à rigidez do mercado de trabalho e aos efeitos de distorção da alocação dos recursos imputáveis aos diversos dispositivos de transferências sociais. A agenda daí deduzida em matéria de políticas públicas e difundida pela Estratégia Europeia para o Emprego, estimulou ou acompanhou uma série de rupturas em relação à norma de emprego em vigor, conforme modalidades próprias, nos dois países até os anos 1980.

Os trabalhos institucionalistas mais recentes (PALIER; THELEN, 2010) sobre a evolução das economias alemã e francesa explicam as mudanças ocorridas pelas complementaridades institucionais entre os sistemas de relações industriais, o mercado de trabalho e os sistemas de proteção social, que, devido à incapacidade ou à recusa dos "insiders" de negociar acordos sobre a flexibilidade, teriam levado a uma mesma dualização do mercado de trabalho nos dois países. Nossa análise se distancia dessa grade de leitura em vários pontos. Em primeiro lugar, centrada nas abordagens discursivas, nossas conclusões mostram o papel-chave representado pela expertise na redefinição das políticas públicas do emprego e da proteção social, retomada por coalizões políticas e sociais que marginalizaram os sindicatos. Em segundo lugar, nossa abordagem teórica leva a afastar a tese de um simples dualismo gerado pela oposição entre os "insiders" e os "outsiders", ressaltando um continuum bem mais geral de fragmentação das normas de emprego, em termos de valorização das qualificações, de relação jurídica com o emprego, de tempo de trabalho, de desigualdades salariais e de difusão de um setor de baixos salários. Em terceiro lugar, nosso quadro de análise 
permite compreender as mutações distintas da norma de emprego na Alemanha e na França, na articulação das dinâmicas originais dos regimes de emprego nacionais e das declinações discursivas nacionais do imperativo do emprego "a qualquer preço". Seja em termos de estagnação dos índices de emprego em equivalente tempo integral, de tipos de contrato de trabaIho, de desigualdades e de pobreza laboriosa, a fragmentação da norma de emprego é mais pronunciada na Alemanha, principalmente devido ao papel atribuído às mulheres no mercado de trabalho, muito especialmente nos serviços de atendimento à pessoa.

\section{Glossário}

BA: $\quad$ Bundesanstalt für Arbeit / Bundesagentur für Arbeit

BDA: $\quad$ Bund der Deutschen Arbeitgeberverbände

BDI: $\quad$ Bund der Deutschen Industrie

CFDT: $\quad$ Confederação Francesa Democrática do Trabalho

CGT: $\quad$ Confederação Geral do Trabalho

CNE: Contrato Nova Contratação

CNPF: $\quad$ Conselho Nacional do Patronato Francês

CPE: $\quad$ Contrato Primeira Contratação

DGB: Deutscher Gewerkschaftsbund

IG-Metall: Industriegewerkschaft Mettallindustrie

INSEE: Instituto Nacional de Estatística e Estudos Econômicos

OCDE: $\quad$ Organização de Cooperação e de Desenvolvimento

Econômico

PME: $\quad$ Pequenas e Médias Empresas

PDS: $\quad$ Partei des Demokratischen Sozialismus

SEE: $\quad$ Estratégia Europeia para o Emprego

RMI: Renda Mínima de Inserção 


$\begin{array}{ll}\text { SMIC: } & \text { Salário Mínimo Interprofissional de Crescimento } \\ \text { SPD: } & \text { Sozialdemokratischer Partei Deutschlands } \\ \text { UE: } & \text { União Europeia } \\ \text { WASG: } & \text { Wahlalternative Soziale Gerechtigkeit }\end{array}$

\section{The fragmentation of the employment standards in Europe: a comparison between Germany and France}

\section{Abstract}

This article proposes a comparative analysis of the changes in the employment standards in France and Germany since the late 1980s. The employment standards which include the performance of the work, its remuneration, methods of assessing qualifications, and job security - are comprehended here as a discursive approach that relates, within the analysis of the public action, the struggle for hegemony between the discourses and the representations of the change in the identity of the actors, the changes in the power relations in the field of public policies, and the modalities of institutionalization of the same. In these countries, the changes in the employment standards that occurred at the turn of the century are the result of a common strategy of maximizing gross indicators of employment, whose conditions of possibility and consequences must be examined within the context of each national system of employment. The systems are based on the articulation of three dimensions (LALLEMENT, 1999): the relationship with the State and the public policies, the evolution of the power relations between interest groups, the forms of competition and the organizational structures in the relevant sectors.

This theoretical approach, developed first, serves to characterize, in a comparative way, the employment systems and standards in France and Germany until the 1980s. The third part empirically summarizes a series of changes in employment that took place in both countries in the recent years, in varying degrees; and highlights some of its consequences in terms of - an uneven - redistribution of the overall volume of work, job insecurity and increased laborious poverty. The final section intends to explain the modalities of the previously discussed fragmentation of the employment standards, as related to the changes in the characteristics of the employment systems in these countries, from the perspective of the discursive change in this field. 
Keywords: Employment standards. Employment policies. Germany. France. Labor market reforms. Discourse. Lisbon Agenda.

\section{Referências}

AEBERHARDT, Romain et al. Le revenu salarial et ses composantes, évolution et inégalités de 1978 à 2005. In: Les salaires en France, édition 2007, collection Références, Insee, 2007.

AUER, Peter; CAZES, Sandrine. Employment Stability in an Age of Flexibility, Evidence form Industrialized Countries. Genève, Bureau international du travail, 2003.

BARBIER, Jean-Claude. The European Employment Strategy, a channel for activating social protection? In: POCHET, Philippe; ZEITLIN, Jonathan (eds.) avec Lars Magnusson. The open method of co-ordination in action, Bruxelles, Bern, Berlin, Peter Lang, 2005.

. Réflexion comparative sur les conditions sociales d'une flexicurité à la française. Regards sur I'actualité, La documentation française, p. 53-64, 2008.

. Stratégie de Lisbonne: les promesses sociales non tenues. CES Working Paper. 2010-18, Paris, 2010.

BERREBI-HOFFMANN, Isabelle et al. Capitalizing on variety: Risks and Opportunities in a New French Social Model. In: BOSCH, Gerhard et al. (eds.). European Employment Models in Flux, Palgrave Mac Millan, cap. 7, 2009.

BEVORT, Antoine; JOBERT, Annette. Sociologie du travail: les relations professionnelles. Paris: Armand Colin, 2008.

BIBOW, Jörg. The Economic Consequences of German Unification. Levy Institut, Public Policy Brief, n. 67, 2001.

BISPINCK, Reinhard (ed.). Wohin treibt die Tarifpolitik? Hambourg: VSA, 2007. BLAIR, Tony; SCHRÖDER, Gerhard. Der Weg nach Vorne für Europas Sozialdemokraten - 08-06-1999.

BOSCH, Gerhard; WEINKOPF, Claudia. Low-wage work in Germany. New York: Russell Sage Foundation, 2008.

BRAUN, Dietmar; GIRAUD, Olivier. Models of Citizenship and Social Democratic Policies. In: BONOLI, G.; POWELL, M (Orgs.). Social democratic party policies in the 1990s. London: Routledge, p. 43-65, 2003.

CAROLI, Eve; GAUTIÉ, Jérôme. Low-Wage Work in France. New-York: Russell Sage Foundation, 2008. 
CARLIN, Wendy; SOSKICE, David. Reforms, Macroeconomic Policy and Performance in Germany, Center for Economic Policy Research, Discussion paper n. $6415,2008$.

CHARGNY ODILE, 2005.

CHEVILLON, Guillaume et al. Désinflation compétitive: le cas allemand 2007. Miméo, Paris, CEPII, 2007.

COLOMB, Fabrice. Les politiques de I'emploi en France dans les années 1990: entre transformations des élites et résistance du référentiel. Congrès de I'AFSP, Section thématique 23, 2009.

COMMISSION EUROPEENNE. L'emploi en Europe, DG emploi et affaires sociales, Bruxelles, 2004, 2008.

. Europe 2020. Une stratégie pour une croissance intelligent, durable et inclusive. Bruxelles, 2010.

DEHOUSSE, Renaud. La méthode ouverte de coordination - quand I'instrument tient lieu de poiltique. In: LASCOUMES, Pierre; LE GALES, Patrick (Orgs.) Gouverner par les instruments. Paris: les Presses Science Po, p. 331-356, 2004.

DÜTHMANN, Anja et al. Arbeitskosten in Deutschland bisher überschätzt, Institut für Makroökonomie und Konjunturforschung, Hans-Bökler Stiftung, Report $\mathrm{n}^{\circ} 11,2006$.

EICHHORST, Werner; PROFIT, Stefan; THODE, Eric. Benchmarking Deutschland: Arbeitsmarkt und Beschäftigungspolitik, Springer Verlag, 2001.

EICHHORST, Werner; MARX, Paul. Reforming German Labor Market Institutions: A Dual Path to Flexibility, IZA discussion paper $n^{\circ} 4100,2009$.

FLECKENSTEIN, Timo. Restructuring welfare for the unemployed: the Hartz legislation in Germany. Journal of European Social Policy, n. 18, p. 177-199, 2008.

GALLIE, Duncan. Production regimes, employment regimes and the quality of work. In: GALLIE, Duncan (Org.). Employment Regimes and the Quality of Work. Oxford: Oxford University Press, p. 1-34, 2008.

GAURON, André. Un cas d'école de changement de référentiel. La politique d'exonération de cotisations sociales. In: GIRAUD, Olivier; WARIN, Philippe (Orgs.) Politiques publiques et démocratie. Paris: La Découverte, p. 199-216, 2008.

GAZIER, Bernard; ZAJDELA, Hélène. 'Making work pay': from justifications to implementations. CES Working Papers, Paris, 2006.

GERNANDT, Johannes; PFEIFFER, Friedhelm. Rising Wage Inequality in Germany, ZEW-Discussion Paper Nr. 06-019, 2006.

GIRAUD, Olivier; LALLEMENT, Michel. L'institutionnalisation des relations professionnelles en RFA. Entreprises et Histoire, n. 16, p. 35-47, 1997. 
GIRAUD, Olivier; LECHEVALIER, Arnaud. Beschäftigung und Einkommen: eine Analyse der französischen Niedriglohnpolitik. In: BRUNKHORST, Ulla ; SOLD, Kaltrin (Orgs.). Frankreich-Themen 2008, DGAP-Schriften zur Internationalen Politik, Baden-Baden: Nomos, p. 83-98, 2008.

HALL, Peter ; SOSKICE, David. An introduction to varieties of capitalism. In: HALL, Peter; SOSKICE, David (Orgs.) Varieties of Capitalism - The institutional foundation of comparative advantage. Oxford: Oxford University Press, p. 1-68, 2001.

HOWARTH, David. Discourse. Buckingham: Open University Press, 2000.

INSEE. Soixante ans de réduction du temps de travail dans le monde. Insee Première, n. 1273, janvier, 2010.

JOBERT, Annette. Les espaces de la négociation collective. Toulouse: Octarès, 2000.

JOBERT, Bruno; THERET, Bruno. France: La consécration républicaine du néo- libéralisme. In: JOBERT, Bruno (Org.). Le tournant néo-libéral en Europe. Idées et recettes dans les pratiques gouvernementales. Paris: L'Harmattan, p. 21-85, 1994.

JOBERT, Annette; HEIDLING, Heckard. Dissolution dans les territoires ou réinvention par les territoires des modèles français et allemand de concertation sociale? In: DUPRE, Michèle; GIRAUD, Olivier; LALLEMENT, Michel (Orgs.) Les modèles sociaux européens en question La France, I'Allemagne face aux nouveaux policy Mix. Bruxelles: Peter Lang, 2011.

KALINA, Thorsten; WEINKOPF, Claudia. Niedriglohnbeschäftigung 2007 weiter gestiegen - zunehmende Bedeutung von Niedrigstlöhnen, IAQ-Report, 2009-05, 2009.

LALLEMENT, Michel. Les gouvernances de I'emploi. Relations professionnelles et marché du travail en France et en Allemagne. Desclée de Brouwer, Paris, 1999.

LEFRESNE, Florence. Les politiques d'emploi et la transformation des normes: une comparaison européenne. Sociologie du travail, n. 47, p. 405-420, 2005.

. Le contrat de travail en question. Regards sur l'actualité, n. 324, octobre, p. 45-56, 2006.

LEWIS, Jane. Recognizing Carework: the need to make policy more care-centred. In: GIRAUD, Olivier; LUCAS, Barbara (eds.). Gouverner les parcours de vie. Politiques du Care en Europe. Presse Universitaire de Rennes (à paraître), 2010.

FERREE, Myra Marx. Framing Equality: the Politics of Race, Class, Gender in the US, Germany, and the Expanding European Union. In: ROTH, Silke (dir.). The Gender Politics of the European Union, Berghahn Publishers, chap. 12, 2008.

. Inequality, Intersectionality and the Politics of Discourse: Framing Feminist Alliances. In: The discursive politics of gender equality: stretching, bending, and policymaking. Londres: Routledge, 2009. 
OECD. Growing Unequal? Income Distribution and Poverty in OECD Countries. Paris: OECD, 2007.

PALIER, Bruno; THELEN, Kathleen. Institutionalizing Dualism: Complementarities and Change in France and Germany. Politics and Society, v. 38, n. 1, p. 119-148, 2010.

RUDISCHHAUSER, Sabine; ZIMMERMANN, Bénédicte. De la critique à l'expertise. La 'modernisation' de l'action publique : le cas du chômage en France et en Allemagne. In: ZIMMERMANN, Bénédicte (Dir.). Les sciences sociales à I'épreuve de I'action - Le savant, le politique et l'Europe. Paris : Editions de la MSH, p. 247-283, 2004.

SABATIER, P.A. Policy Change over a Decade or More. In: SABATIER, P.A.; JENKINS-SMITH, H (Dir.). Policy Change and Learning. An Advocacy Coalition Approach. Boulder: Westview Press, p. 13-39, 1993.

Sachverständigenrat für die Begutachtung der gesamtwirtschaftlichen Entwicklung. Widerstreintende Interessen - Ungenutzte Chancen, Jahresgutachten 2006/2007, Wiesbaden, p. 325-343, 2007.

SALAIS, Robert. Europe and the Deconstruction of the Category of 'Unemployment', Archiv für Soziologie, 47, p.371-401, 2007.

SCHARPF, Fritz; SCHMIDT, Vivien A. Welfare and Work in the Open Economy. From Vulnerability to Competitiveness. Oxford: Oxford University Press, 2000.

SCHMID, Günther. Wege in eine neue Vollbeschäftigung. Übergangsarbeitsmärkte und aktivierende Arbeitsmarktpolitik, Frankfurt am Main, Campus Verlag, 2002.

SEELEIB-KAISER, Martin; FLECKENSTEIN, Timo. Discurse, Learning and Welfare State Change: The Case of German Labour Market Reforms, Social Policy and Administration, v. 41, n. 5, p.427-448, 2007.

SIEGEL, Nico A. Baustelle Sozialpolitik. Campus Verlag, 2002.

SINN, Hans-Werner. Die Basar-Ökonomie. Deutschland: Exportweltmeister oder Schlusslicht?, Econ: Berlin, 2. Auflage, 2005.

THELEN, Kathleen. Union of Parts: Labor Politics in Postwar Germany. Cornell University Press, 1991.

VAIL, I. Mark. "From 'welfare without work' to buttressed liberalization': the shifting dynamics of labor market adjustment in France and Germany", European Journal of Political Research, v. 47, p.334-358, 2008.

Recebido: 10/06/2010

Aceite final: 19/08/2010 